SEES Research Series

Research Article IV

\title{
An Investigation into the Occupational Exposure of Service Station Pump Attendants to Low Levels of Benzene Present in Gasoline Vapour during Refuelling
}

\author{
Marcelle Chan-A-Sue, Isidro Espinosa \& Shanomae Rose
}

DOI: https://doi.org//0.52377/YJOT9686

\begin{abstract}
This study covers an investigation into occupational exposure to benzene emitted from gasoline during refuelling in Greater Georgetown. Pump attendants are particularly vulnerable as they are constantly exposed to gasoline vapour during their work day. Two mathematical models were used to determine a concentration of benzene to which gasoline pump attendants could potentially be exposed. Then the potential health implications of this exposure were examined. The benzene exposure concentrations were found to be $1.5 \mathrm{mg} / \mathrm{m}^{3}$ and $0.4 \mathrm{mg} / \mathrm{m}^{3}$ for Shell and Guyoil Service Stations respectively, which are within the permissible exposure limits set by the developed world (e.g. by the National Institute for Occupational Safety and Health in the United States of America and countries of the European Union). Due to certain limitations of this research, future research using more accurate methods is required to determine a general occupational exposure for all pump attendants in Greater Georgetown at any given time, and measures to reduce exposure should be considered.
\end{abstract}

Keywords: occupational exposure, benzene, refuelling, gasoline

\section{Introduction}

Background

In urban areas that have a higher population density and traffic-related air pollution, traffic is the most important source of air benzene concentrations (Vlachokostas et al., 20I I). Research has found that gas stations are the second major source of BTEX emissions (benzene, toluene, ethyl benzene and xylene) (Correa et al., 2012, p. 164). Benzene emissions are always present in vapour form in vehicle fuel tanks and are forced out when the tank is filled with liquid fuel (U.S. Environmental Protection Agency Office of Mobile Sources, p. 3), with fuel benzene content having the greatest influence on benzene refuelling emissions into the atmosphere (Laing, 1986, p. 5). Presently, the benzene content in gasoline varies from less than $1 \%$ to $5 \%$ vol, depending on fuel quality, countries' legislation and season (Verma \& Tombe, 2002). 
It is very important to monitor benzene levels and assess air quality at a local scale since benzene has been found to have relatively high population risks (e.g. development of cancer) in various countries among hydrocarbon air pollutants (Vlachokostas et al., 20II, p. 2585). Many of the toxicological effects due to gasoline exposure have been attributed to specific components of the mixture like benzene. Benzene is dangerous to human health as its toxic effects are mainly on the haematopoietic system and the immune system. Benzene has also been classified as a group $A$ human carcinogen by the Environmental Protection Agency (the United States of America). In addition to occupational exposure to benzene, persons can increase their exposure and toxicity to benzene through lifestyle choices such as smoking and alcohol consumption.

Gas station service attendants are a particularly vulnerable group as they can be exposed to low levels of benzene during the refuelling of vehicles (at the vehicle/nozzle interface), and from ambient air concentrations of benzene, especially if they work in an urban area such as Georgetown, Guyana where there is heavy vehicular traffic as compared with other parts of the country. This occupational exposure is defined as the concentration of potentially harmful chemical, physical, or biological agents in the work environment that an employee can be exposed to during a specified period, i.e. the 8 hour work period (OECD, 1993, p. 12 and Reference.MD, 2012).

Within the last ten years Guyana has seen a significant increase in the importation and registration of vehicles in the country (Guyana Revenue Authority, 2010). These vehicles require refuelling, and so pump attendants today are being utilized more frequently to refill these vehicles. As such exposure to benzene during refuelling has increased over the years. Other potential sources of exposure are vapours from vehicle fuel tanks, fuel soaked rags or accidentally soiled clothing, and exhaust gases from tankers delivering fuel (Carrieri et al. 2006, p. 147).

Relevant agencies such as The Environmental Protection Agency (Guyana) and the Ministry of Labour, Human Services and Social Security (Guyana) lack the capacity to monitor benzene emissions and exposure concentrations. As a result, there has been no research on the occupational exposure to benzene during vehicle refuelling in Guyana. Therefore, it is unknown if pump attendants are being exposed to dangerous levels of benzene during their time at work. The main aims of this research were to estimate the occupational exposure of service station pump attendants to benzene during refuelling using mathematical models and to determine the possible health implications due this type of chronic low level exposure.

\section{Literature Review}

There are many differing views by international health agencies and scientific bodies on the health hazard due to the inhalation of gasoline (Keenan et al., 2010, p. 293). Gasoline has been classed as a possible human carcinogen by the International Agency for Research on Cancer (IARC) based on the establishment of benzene (Group I Carcinogen, IARC, 1987) and I, 3 butadiene as carcinogens. However, for benzene to be toxic it has to be metabolized to reactive intermediates (Snyder et al., 1993, p. 293) in the liver. Since benzene is dangerous to human health, occupational limits have been set e.g. the National Institute for Occupational Safety and Health in the United States of America set the occupational limit value to I ppm or $3.25 \mathrm{mg} / \mathrm{m}^{3}$.

Methods Used to Determine Occupational Benzene Exposure 
There have been several studies done which try to assess the occupational exposure to benzene. The methods employed some form of scientific testing in order to estimate the concentration of benzene that persons were exposed to during refuelling of vehicles. Models (mathematical and computer) were also used to estimate exposure. For instance, a study by Karakitsios et al. (2007) in Greece used a computer model to predict an exposure to benzene for filling station employees and compared the results to those obtained from passive sampling. In another study done by Vainiotalo et al. (1999) on customer exposure to benzene during gasoline refuelling, there was also comparison of exposure between a rural and an urban gas station. Both gas stations had stage I vapour recovery systems that collect vapours during unloading but not stage II recovery, which collects vapours released from a vehicle's gasoline tank during refuelling. Even though the study was done on customers, the method can be applied to gas station service attendants. Air samples were collected from the customers' breathing zones in charcoal tubes during refuelling. Samples were then analysed in a laboratory and the concentration of benzene determined.

Exposure to benzene can also be determined by means of biological testing by testing for certain biological indicators. Phenol is the main metabolite of benzene, and it has been found in the literature that the phenol concentration in the urine of exposed workers can be used as an index of internal dose because the urinary level is highly correlated with external benzene exposure (Celik \& Akbas, 2005, p. II0). In the research done by Celik and Akbas (2005, p. II0) the mean urinary phenol levels of the pump attendants could be attributed to occupational exposure when the subjects considered shared the same demographic parameters e.g. diet, smoking, ingestion of medicine.

\section{Health Consequences Due to Low Level Occupational Exposure}

Low level occupational exposure to air benzene is considered to be less than I0ppm (ATSDR, 2000 , p. 13). Chronic toxicity in humans occupationally exposed to benzene include haematological (aplastic anaemia and pancytopenia), mutagenic (chromosomal aberrations), and carcinogenic (acute non- lymphocytic leukaemia) (Duarte- Davidson et al., 200 I, p. 3). "Most of the evidence for this derives from industrial studies of workers exposed to benzene, often as a constituent of a complex mixture."

In a study done by Terry et al. (2005) in the U.S. and Canada statistically significant associations were found between acute myeloid leukaemia (AML) and several occupations, one of which included gas station pump attendants. However, one study which focused on the risk of cancer and exposure to gasoline vapours in the Nordic countries (i.e. Denmark, Norway, Sweden, France and Finland) concluded that pump attendants with average level of exposure to benzene <lppm, showed no excess risk of leukaemia, specifically AML (Lynge et al., 1997, p. 457). Interestingly though, they had an elevated risk of other types of cancer such as pharyngeal, laryngeal, lung etc. (Lynge et al., 1997, p. 457).

Generally, there is conflicting evidence on potential haematological effects of benzene at low concentration levels (Swaen et al. 2010, p. 94). A study conducted concluded that petrol (containing benzene) exposure can be associated with geno-toxic effects on the lymphocytes (Celik \& Akbas, 2005, p. I I0). The results showed that the proliferation of human lymphocytes was significantly inhibited, indicating immune-suppression in the pump attendants when compared to the control group (Celik \& Akbas, 2005, p. 109). On the other hand, Swaen et al. (2010) 
conducted a study in the Netherlands which found that workers exposed to low benzene concentrations were not at risk for haematological effects.

Additionally, benzene has been shown to cause sperm aneuploidy at exposures less that I0ppm, even as low as less than Ippm (Xing et al., 2010, p. 833). This can indicate that the current PEL for benzene is not sufficient enough to protect men from reproductive damage.

\section{Methodology}

\section{Description of Study Area}

The petrol companies identified for this research project were Sol Guyana Inc., the Guyana Oil Company Limited and Texaco located within greater Georgetown. Initially, the study was to be done at these three main petrol companies. However, permission to conduct the research was only given by the head offices of Sol Guyana Inc. and the Guyana Oil Company Limited. The research was done at seven service stations, as this was the total number of Shell and Guyoil Service Stations within Greater Georgetown. Georgetown is one of the six urban municipalities of Guyana (NDS, 200I, chapter 2I) and is the capital city. Greater Georgetown is $39 \mathrm{~km}^{2}$ encompassing Cummings Lodge on the East Coast of Demerara and Agricola on the East Bank of Demerara (Urban Environment Outlook, GEO Georgetown, 2009, p. 13). Greater Georgetown was chosen because more of the gas/service stations would be captured in the survey. Another reason for choosing this urban area is that pump attendants there would be more susceptible to benzene exposure due to the higher traffic flow.

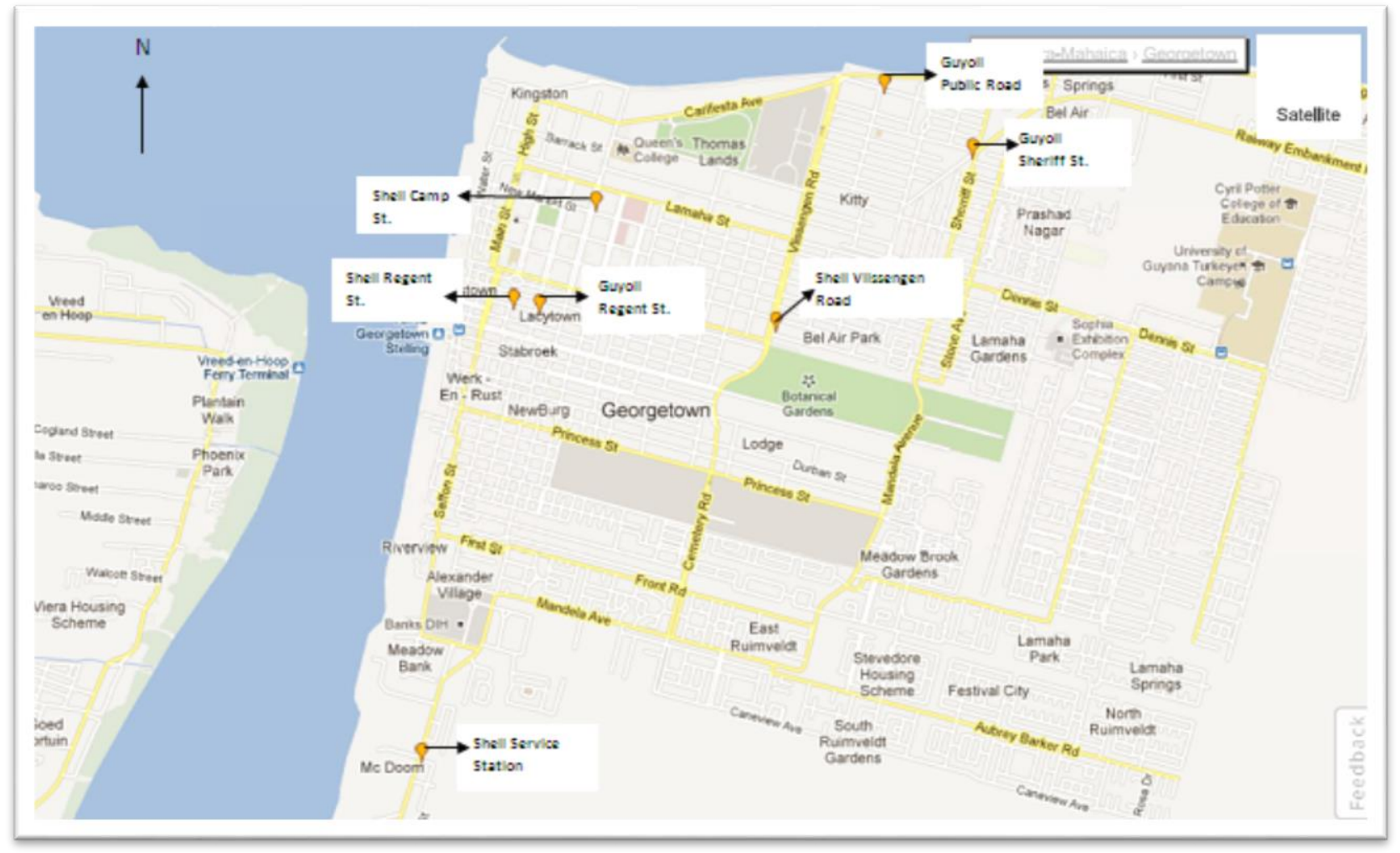

Figure I: Location of the Service Stations, Greater Georgetown. Source: Google Earth 


\section{Experiment Design}

Temperature was tested using a $\mathrm{HACH}$ pH meter as this had the thermometer or temperature sensor attached to it. The meter was attached to a display screen (series: HQ40d). Since the emission of benzene would be affected by temperature, it was decided that data should be obtained to determine the lowest and highest benzene concentration that the pump attendants would be exposed to. Therefore, temperature measurements were taken at the highest temperature, at the lowest temperature and at a temperature between those two.

In order to determine the time at which measurements should be taken, data on temperature variation throughout the day was needed. This information was obtained from the Hydrometerological Office of the Ministry of Agriculture, Guyana. The data set on temperature obtained dated from the 19 April 2012 to 27 April 2012. From this data set it was determined that the lowest temperature for Georgetown fell between 05:00hrs and 06:00hrs, and that the highest temperature fell between 12:00hrs and 14:00hrs. A median temperature was found to be between 10:00hrs and 11:00hrs. Thus, the time intervals chosen for taking measurements were 05:00-06:00hrs, 10:00-II:00hrs, and 12:30-13:30 hrs.

It was decided that temperature measurements would be taken for three days at each service station. During each time interval, three measurements would be taken. The vehicles temperatures that were measured included cars, pickups and mini-buses. Temperature measurements were only taken at five of the seven gas stations because the gasoline damaged the protective plastic covering the thermometer. Before the measurements of temperature were taken, the general environmental conditions of each service station were recorded. The environmental conditions (e.g. windy, overcast) at each time of testing were also recorded.

Verbal consent to measure the temperature was sought from the customers that were refuelling their vehicles during the testing intervals. Once they agreed, the tank was opened and the thermometer was immediately placed in the vehicle tank i.e. before refuelling commenced. The temperature and time were then recorded.

\section{Calculation of Benzene Emission Factor}

In 1986, a study by Laing (United States (US) Environmental Protection Agency) developed an empirical relationship between benzene refuelling emissions and fuel/ temperature conditions. His report on the study presented the results of an Environmental Protection Agency test program designed to characterize benzene refuelling emissions. The study also examined several other available benzene refuelling emission studies to form a combined data base (Laing, 1986, $p$. I). A relationship between benzene refuelling emissions and three significant parameters was then developed by fitting a multivariate linear regression model these combined data.

According to Laing (1986, p. 5), "the relationship has several important uses such as the estimation of a national benzene rate." In order to estimate a total emission factor for benzene during refuelling a spillage factor must be taken into account. This prediction equation (model) used to calculate the benzene emission factor for this research was as follows: 
$\mathrm{E}_{\mathrm{r}}=(0.038 * \% \mathrm{Bz})-\left(1.60 \times 10^{-4} * \mathrm{~T}_{\mathrm{D}}\right)-\left(4.24 \times 10^{-4} * \Delta \mathrm{T}\right)$

Where;

$E_{r}=$ Emission rate in grams benzene/ gallon (important to note here is the type of gallon used in the equation)

$\% \mathrm{Bz}=$ Liquid fuel benzene concentration (\% wt.), expressed as a percent not a decimal fraction

$\mathrm{T}_{\mathrm{D}}=$ Dispensed fuel temperature $\left({ }^{\circ} \mathrm{F}\right)$

$\Delta \mathrm{T}=$ Difference between fuel tank temperature and dispensed fuel temperature $\left({ }^{\circ} \mathrm{F}\right)$.

The benzene concentration obtained from the certificate of quality was in \%v. Therefore there had to be a conversion from \%v to \%wt. This was done using the following conversion:

$\% w t .=\% v(A$ in $B) \times$ density $A /$ density $B\left(\right.$ at $\left.15^{\circ} \mathrm{C}\right)$; where $A=$ benzene and $B=$ gasoline The density $(\mathrm{kg} / \mathrm{L})$ of the gasoline at $15^{\circ} \mathrm{C}$ was also obtained from the certificate of quality.

The model (Laing, 1986) required the temperature to be in ${ }^{\circ} \mathrm{F}$, but the temperature was measured in ${ }^{\circ} \mathrm{C}$ during data collection. This was converted to ${ }^{\circ} \mathrm{F}$ using a "Convert.exe" computer programme based on the formula ${ }^{\circ} \mathrm{F}=\left({ }^{\circ} \mathrm{C} * 5 / 9\right)+32$.

Considerations and Limitations

- The model does not take into consideration the fuel delivery rate

- The model does not take into consideration the vehicle fuel system configuration

- Measurements were taken at atmospheric pressure

- The liquid gasoline and the gasoline vapour were assumed to be the same temperature due to limitation with equipment as the temperature sensor was too big to go into the vehicle tank.

\section{Calculation of an Estimated Benzene Exposure}

The exposure concentration was calculated using a Gaussian model of atmospheric dispersion which determines exposure. It is a mathematical model of atmospheric dispersion that tries to simulate the behaviour of the plume emitted from the ground level point source, or in chimneys with specific height. The model chosen calculates concentration in the air from a ground level source.

The estimated benzene exposure concentration at $0.5 \mathrm{~m}=$

$\mathrm{C}(\mathrm{x}, 0,0)=\mathrm{Q} / \pi \mathrm{u} \sigma_{\mathrm{y}} \sigma_{\mathrm{z}}$

Where;

$\mathrm{Q}=$ emission rate in $\mathrm{g} / \mathrm{s}$

$\mathrm{u}=$ wind speed in $\mathrm{m} / \mathrm{s}$

$\sigma_{y}=3.05 \mathrm{~m}$, normal deviation in direction $y$

$\sigma_{\mathrm{z}}=0.035 \mathrm{~m}$, normal deviation in direction $\mathrm{z}$

(Source: Wark and Warner, 200I, p. I6I)

\section{Considerations and Limitations}

- The flow rate was not measured but was obtained from the head offices of the service stations. 
- Wind speed data was used to find an average wind speed for Greater Georgetown due to equipment limitation. Average wind speed for Greater Georgetown (u) $=8.2 \mathrm{~m} / \mathrm{s}$ (Hydrometerological Office).

- The model calculates atmospheric concentration from an emission source at ground level along a horizontal distance of $0.5 \mathrm{~m}$. This distance was chosen because it is assumed that pump attendants will most likely operate within this distance from the pumps. In this instance the ground level can be considered as $\mathrm{Im}$ high. This height was chosen because according to CAPCOA (1997, p. 13) for refuelling emissions, the release height was chosen to be one meter. This is the same height as most car nozzle receptors.

- The values for $\sigma_{y}$ and $\sigma_{z}$ were calculated via extrapolation.

\section{Results and Discussion}

Figures 2 and 3 show the variation benzene emission factor throughout the day. The average emission factor for the Shell service stations was $0.02763 \mathrm{~g}$ benzene/ gallon, and for Guyoil it was $0.0350 \mathrm{I} g$ benzene/ gallon.

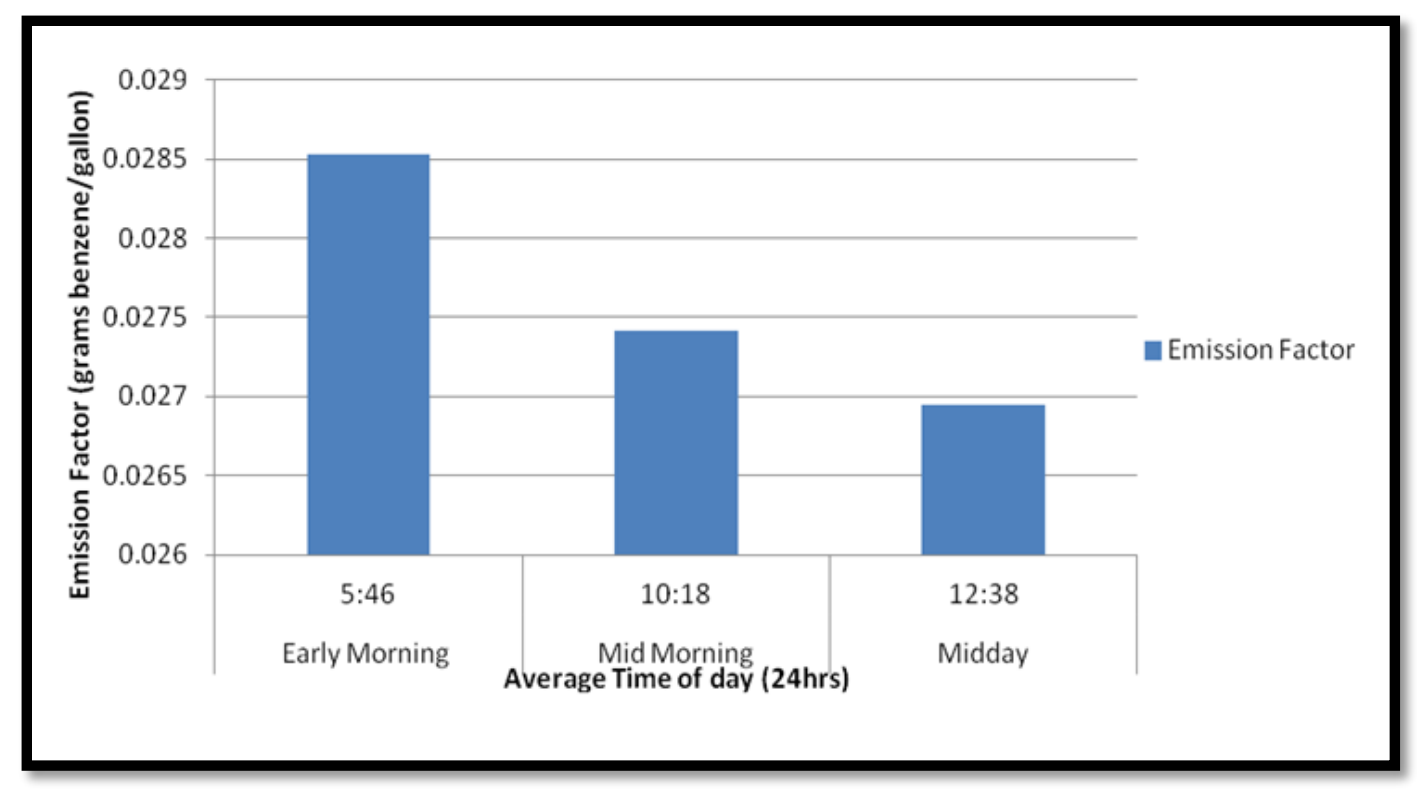

Figure 2: Benzene Emission Factor for Shell Service Stations 


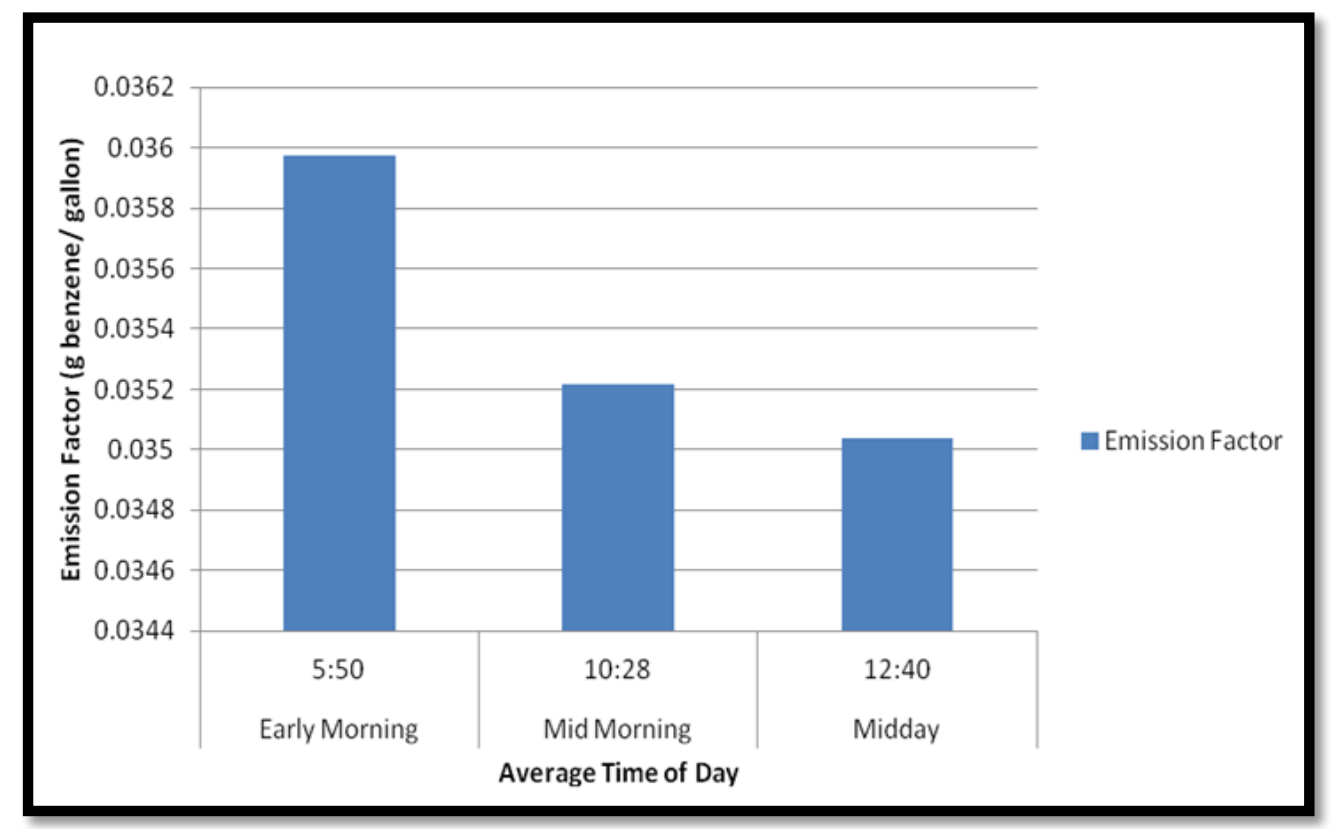

Figure 3: Benzene Emission Factor for Guyoil Service Stations

The estimated occupational exposure of pump attendants to benzene in gasoline during refuelling was determined to be $1.5 \mathrm{mg} / \mathrm{m}^{3}$ for Shell pump attendants and $0.4 \mathrm{mg} / \mathrm{m}^{3}$ for Guyoil pump attendants. In addition, results show that with a higher emission rate the exposure is lower (Guyoil) and with a lower emission the exposure is higher (Shell). This result indicates that the benzene emission factor during refuelling does not directly correspond to exposure concentration (i.e. a higher emission factor does not result in higher occupational exposure). There are other factors that would influence benzene exposure during vehicle refuelling. Based on the calculations, this result can be attributed to the flow rate of the gasoline during refuelling, which depends on the model of the dispensing pumps the service stations use.

The gasoline pumps at Shell service stations dispense gasoline at a higher rate (8-10 gallons/ minute) than the pumps at Guyoil service stations ( 2 gallons/minute) due to their different specifications or because they use different pump models, and so the pump attendants at the Shell service stations were exposed to a higher concentration of benzene than the ones at Guyoil service stations. This results because a greater volume of gasoline could be pumped in a minute. Therefore, it may be assumed that if Guyoil were to change the model of their dispensing pumps to one with a flow rate similar to that of Shell, then Guyoil pump attendants would be exposed to a higher benzene concentration during vehicle refuelling.

The occupational exposure determined for pump attendants in Greater Georgetown were well within the permissible exposure limit (8hr Time Weighted Average) set by the countries in the developed world e.g. the U.S. Occupational Safety and Health Administration which set a limit of 
Ippm or $3.2 \mathrm{mg} / \mathrm{m}^{3}$ (Figure 4). As such the pump attendants at Shell and Guyoil service stations were not exposed to dangerous levels of benzene based on these results.

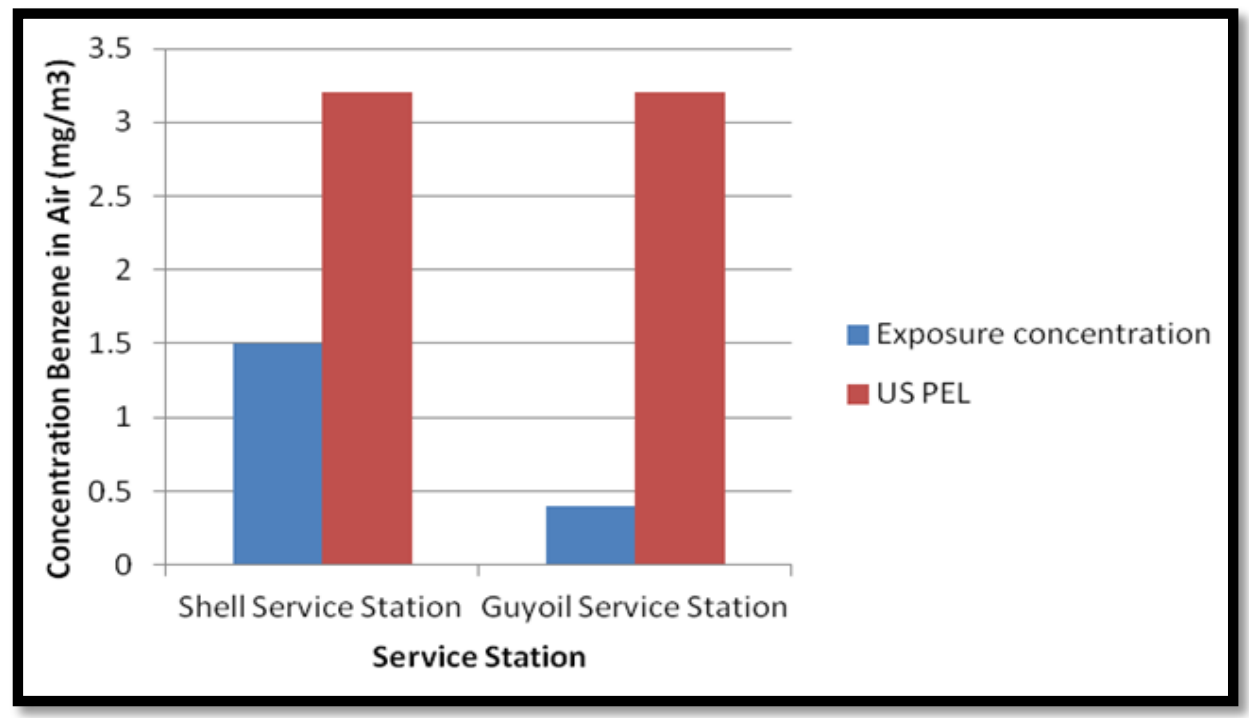

Figure 4: Calculated Occupational Exposure Concentration at Shell and Guyoil Service Stations and the US Permissible Exposure Limit

However, their health may still be at risk since the literature does suggest statistically significant associations between working as a pump attendant for at least one year and an increased risk of acute myeloid leukaemia, AML, (e.g. Terry et al., 2005 and Lynge et al., 1997). It is important to note that even though benzene is the primary compound in gasoline or petroleum associated with the risk of AML, exposure to multiple compounds in gasoline can contribute to an increased risk of AML specifically (Terry et al., 2005). As Lan et al. (2004) indicated immune suppression can occur at exposure levels below Ippm and so pump attendants may be more susceptible to infections than a non-exposed group of persons. Male pump attendants in particular may be susceptible to benzene's damaging effects as Xing et al. (2010) indicated that men who were exposed to less than IPpm air benzene had statistically significant elevated rates of sperm aneuploidy. This factor has implications for the viability, development and health of their children.

It is important to consider safeguarding pump attendants against benzene exposure, even though the exposure concentration was found to be within U.S. permissible exposure limits. The reason for this is that these results are only a theoretical approximation. The benzene concentration varies in the gasoline imported in different shipments, and so pump attendants may be exposed to higher or lower concentrations than those determined in this research at different times throughout the year.

The emission factor calculated for benzene may be inaccurate because the actual temperature of the liquid gasoline was not measured because of an equipment limitation. It is possible that a lower temperature was measured because of cooler air rushing into the vehicle tank when it was opened. Also a technical error could have occurred because the equipment (temperature sensor) 
could not accurately measure the temperature in the vehicle fuel tank as well as that of the dispensed fuel. This too could have resulted in an inaccurate calculation for the emission factor. Lack of a spillage factor for Guyana, resulting in the use of the U.S. EPA (Laing, 1986) spillage factor would also cause the emission factor calculated to be inaccurate. Because the emission factor calculated may have been inaccurate, the occupational exposure calculated would also have been inaccurate to some degree as its value was dependent on the emission factor calculated (i.e. when determining $\mathrm{Q})$.

The estimated exposure may also be inaccurate because the actual wind speed in each service station was not measured because of the technical limitation of equipment; instead an average wind speed for Georgetown was used. It is likely that the wind speed around the pump islands in the gas stations are not this high due to vehicles in the service station blocking the wind. The physical environment may also contribute to reducing the wind speed especially in commercial areas that have buildings with more stories. A higher wind speed would result in a lower occupational exposure, and so the estimated occupational exposure may be underestimated.

\section{Conclusion}

The occupational exposure to benzene was found to be $1.5 \mathrm{mg} / \mathrm{m}^{3}$ for Shell service station pump attendants and $0.4 \mathrm{mg} / \mathrm{m}^{3}$ for Guyoil service station pump attendants. This was found to be within the PEL of $3.2 \mathrm{mg} / \mathrm{m}^{3}$ set by the US Occupational Safety and Health Administration. These results are a theoretical approximation of what pump attendants in Greater Georgetown may be exposed to, and is only specific for the liquid benzene concentrations in the liquid gasoline during time period in which the research was done. Precautionary measures should still be taken because the literature suggests that the health of pump attendants (working for at least one year) is at risk. Therefore installation of Stage II vapour recovery systems should be considered.

There needs to be more research done to investigate occupational exposure to benzene. More accurate methods, such as those presented in the literature, should be used. Most methods use activated charcoal to absorb benzene from the air in the service station followed by gas chromatography/mass spectrometry analysis to determine the concentration of benzene to which pump attendants are exposed. There also needs to be accurate collection of data when mathematical or computer models are used.

\section{Acknowledgements}

Sincere thanks are expressed to the staff of the head offices of Sol Guyana Inc., the Guyana Oil Company, the managers of the Shell Service Stations, and the pump attendants at the respective service stations.

\section{References}

Agency for Toxic Substances and Disease Registry, 2000. Benzene toxicity: case studies in environmental medicine. Available at: 
<http://www.atsdr.cdc.gov/csem/benzene/docs/benzene.pdf> [Accessed: 2 December $20 \mathrm{II}]$.

Agency for Toxic Substances and Disease Registry. Routes of Exposure, Module 2. Available at: <http://www.atsdr.cdc.gov/training/toxmanual/pdf/module-2.pdf> [Accessed I 9 June 20I2].

Adami, G. et al., 2006. Penetration of benzene, toluene and xylenes contained in gasoline through human abdominal skin in vitro. Toxicology in Vitro, 20, pp. I32 I-I330.

Akintonwa, A. and Oladele, T.T., 2003. Health effect of exposure to hydrocarbon on petrol filling station attendants in Lagos. Nigerian Quarterly Journal of Hospital Medicine, I 3 (I-2), Pp. 88-92.

Alcohol content database. Available at: <http://www.alcoholcontents.com/> [Accessed: I4 June 20I2].

Barbieri, A. et al., 2008. Urinary biomarkers and low level environmental benzene concentration: Assessing occupational and general exposure. Chemosphere, 74, pp. 64 69.

Boogard, P.J. and van Sittert, N.J., 1996. Suitability of S-phenyl mercapturic acid and trans-transmuconic acid as biomarkers for exposure to low concentrations of benzene.

Environmental Health Perspectives, I04 (6), Pp. II I I-II 57.

Brugnone, F. et al., 1999. Benzene in blood as a biomarker of low level occupational exposure. Science of the Total Environment, 235( I-3), pp. 247-252.

Carrieri M. et al., 2006. Comparison of exposure assessment methods in occupational exposure to benzene in gasoline filling- station attendants. Toxicology letters, 162, Pp. I46-I 52.

Capleton, A.C. and Levy, L.S., 2005. An overview of occupational exposures and occupational exposure limits in Europe and North America. Chemico-Biological Interactions, I53-154, Pp. 43-53.

Celik, A. and Akbas, E., 2005. Evaluation of sister chromatid exchange and chromosomal aberration frequencies in peripheral blood lymphocytes of gasoline station attendants. Ecotoxicology and Environmental Safety, 60 (I), pp. 106-I I 2.

Correa, S. et al., 2012. The impact of BTEX emissions from gas stations into the atmosphere. Air Pollution Research, 3, pp. 163-169.

Egeghy, P.P. et al., 2000. Environmental and Biological Monitoring of Benzene during SelfService Automobile Refuelling. Environmental Health Perspectives, 108 (I2), Pp. II951202.

Environmental Protection (Air Quality) Regulations 2000, Guyana.

Fustinoni, S. et al., 2012. Environmental and lifestyle factors affect benzene uptake biomonitoring of residents near a petrochemical plant. Environmental International, 39 (I), PP. 2-7.

Glass, D.C. et al., 2003. Leukemia Risk Associated with Low- Level Benzene Exposure. Epidemiology, 14 (5), pp. 569-577.

Karakitsios, S.P. et al., 2007. Assessment and prediction of exposure to benzene of filling station employees. Atmospheric Environment, 4I (40), pp. 9555-9569.

Keenan et al., 2010. Gasoline: A complex mixture, or a dangerous vehicle for benzene exposure? Chemico-Biological Interactions, I 84 (I-2), Pp. 293-295.

Korte, J. et al., 2000. The contribution of benzene to smoking induced leukaemia. Environmental Health Perspectives, 108, pp. 333-339. 
Laing, P.M., 1986. Factors Influencing Benzene Emissions from Passenger Car Refuelling. SAE International Papers.

Lan, Q. et al., 2004. Hematotoxicity in workers exposed to low levels of benzene. Science, New Series, 306 (5702), pp. I774- I776.

Lynge, E. et al., 1997. Risk of cancer and exposure to gasoline vapours. American Journal of Epidemiology, 145 (5), pp. 449-458.

Medinsky, M.A. et al., 1994. Critical issues in benzene toxicity and metabolism: The effect of interactions with other organic chemicals on risk assessment. Environmental Health Perspectives, 102 (9), pp. I19-124.

National Development Strategy, Chapter 21: Urban Development, 200I. Available at: <http://www.sdnp.org.gy/nds/chapter2I.html> [Accessed I4 June 20I2].

Onursal, B. and Gautam, S.P., 1997. Vehicular air pollution: Experiences from seven Latin American urban centers. World Bank. Available at: <http://www.rhd.gov.bd/Documents/ExternalPublications/WorldBank/TransSectPub/cont ents/documents/BI I.pdf> [Accessed I4 June 20I2].

Organisation for Economic Co-operation and Development, 1993. Occupational and Consumer Exposure Assessments. Available at: <http://search.oecd.org/officialdocuments/displaydocumentpdf/?cote=ocde/gd(93) I 28\&d oclanguage $=$ en $>$ [Accessed II January 20I3].

Reference.MD, 2012. Occupational Exposure. Available at: <http://www.reference.md/files/D016/mD0 I6273.html> [Accessed: II January 20 I3].

Shell Company, 2006. Material Safety Data Sheet.

Snyder, R. et al., 1993. The toxicology of benzene. Environmental Health Perspectives, 100, PP. 293-306.

Sol Guyana Inc., 20I I. Certificate of Quality Sol Guyana Inc., 2012. Certificate of Quality

Srivastava, A. et al., 2005. Emissions at urban petrol retail distribution centres in India (Delhi and Mumbai). Environmental Monitoring and Assessment, 109, pp. 227-242.

Steffen, C. et al., 2004. Acute childhood leukaemia and environmental exposure to potential sources of benzene and other hydrocarbons: A case-control study. Occupational and Environmental Medicine, $6 \mathrm{I}$ (9), Pp. 773-778.

Swaen, G.M.H. et al., 2010. Low level occupational benzene exposure and hematological parameters. Chemico-Biological Interactions, I84, pp. 94-100.

Terry P. D. et al., 2005. Occupation, hobbies, and acute leukaemia in adults. Leukemia Research, 29, pp. $117-1130$

The Guyana Oil Company Ltd., 20I I. Certificate of Quality.

The Guyana Oil Company Ltd., 2012. Certificate of Quality.

Toxics Committee of the California Air Pollution Control Officers Association (CAPCOA), 1997. Air Toxics "Hot Spots” Program: Gasoline Service Station Industry-wide Risk Assessment Guidelines. Available at: <http://www.arb.ca.gov/ab2588/rrapiwra/GasIWRA.pdf> [Accessed I 4 June 2012]

United States Environmental Protection Agency, 1994. Automobile emissions: An overview, Office of Mobile Sources. Available at: <http://www.epa.gov/oms/consumer/05autos.pdf> [Accessed: 6th June 2012]. 
---, 1989. Estimating air emissions from petroleum UST cleanups. Office of Underground Storage Tanks, Washington, D.C. Available at: <http://www.epa.gov/oust/pubs/airemiss.pdf> [Accessed I 4 June 20I2].

---. Mobile Source Emissions - Past, Present and Future, Glossary. Available at: <http://www.epa.gov/otaq/invntory/overview/definitions.htm> [Accessed I4 June 20I2].

---. Pollutants: Hydrocarbons <http://www.epa.gov/oms/invntory/overview/pollutants/hydrocarbons.htm> [Accessed: 6 June 20I2].

---, 1991. Technical Guidance- Stage II Vapour Recovery Systems for Control of Vehicle Refuelling Emissions at Gasoline Dispensing Facilities. Available at: $<$ http://www.epa.gov/ttn/atw/gasdist/technica.pdf> [Accessed 7 December 20I I].

---, 2006. Toxicity and Exposure Assessments for Children's Health Chemical Summary: Benzene. Available at: <http://www.epa.go/teach/> [Accessed I December 20II].

Vainiotalo, S. et al., 1999. Customer exposure to MTBE, TAME, C6 Alkyl Methyl Ethers, and benzene during gasoline refuelling. Environmental Health Perspectives, I07 (2), Pp. I33140.

Verma, D.K. and Tombe, K., 2002. Benzene in gasoline and crude oil: occupational and environmental implications. AlHA J, 63 (2), pp. 225-230.

Vlachokostas, C. et al., 20II. Combining regression analysis and air quality modeling to predict benzene concentration levels. Atmospheric Environment, 45, pp. 2585-2592.

Wark, K. and Warner, C., 200I. Contaminacion Del Aire: Ogrigen y Control. Mexico: Editorial Limusa Grupo Noriega Editores.

Xing, C. et al., 20I0. Benzene exposure near the US permissible limit is associated with sperm aneuploidy. Environmental Health Perspectives, II8 (6), pp. 833-839. 